\title{
Recurrent Facial Erythema with Cytotoxic T Cell Infiltration as a Possible Reactive Eruption in a Human T-Cell Lymphotropic Virus Type 1 Carrier
}

\author{
Yasuhiro Kaneko Kazuki Tatsuno Toshiharu Fujiyama Taisuke Ito \\ Yoshiki Tokura
}

Department of Dermatology, Hamamatsu University School of Medicine, Hamamatsu, Japan

\section{Key Words}

Adult T cell leukemia/lymphoma - Carrier · Human T-cell lymphotropic virus type 1 - Reactive eruption $\cdot \mathrm{T}$ cell

\begin{abstract}
Human T-cell lymphotropic virus type 1 (HTLV-1) induces adult T cell leukemia/lymphoma (ATLL), HTLV-1-associated myelopathy/tropical spastic paraparesis (HAM/TSP) and carrier. Approximately half of ATLL patients have direct skin involvement of neoplastic cells. However, there exist HTLV-1-associated reactive eruptions with a predominant infiltrate of nonneoplastic CD8 + T cells in ATLL, HAM/TSP and carrier. A 50-year-old Japanese female HTLV-1 carrier had several episodes of itchy, indurated erythema that occurred diffusely on the face and neck, lasted for 2 weeks and spontaneously subsided without sequelae. Histopathologically, CD3 + T cells infiltrated the upper dermis, and part of the infiltrating cells were CD4+CD25+, sharing the phenotype with ATLL neoplastic cells. An aggregate of CD8+ T cells bearing the cytotoxic molecule TIA-1 was also present. It is possible that skin-affinitive HTLV-1+CD4+ T cells propagated and subsequently disappeared as a result of cytotoxic $\mathrm{T}$ cell attack.

(C) 2015 S. Karger AG, Basel
\end{abstract}




\section{Case Reports in Dermatology}

Kaneko et al.: Recurrent Facial Erythema with Cytotoxic T Cell Infiltration as a Possible Reactive Eruption in a Human T-Cell Lymphotropic Virus Type 1 Carrier

\section{Introduction}

Human T-cell lymphotropic virus type 1 (HTLV-1) induces adult T cell leukemia/lymphoma (ATLL), HTLV-1-associated myelopathy/tropical spastic paraparesis (HAM/TSP) and carrier [1, 2]. ATLL is a mature CD4+CD25+CCR4+ T cell neoplasm [3]. HTLV-1 infection is prevalent in southern Japan, especially in Kyushu, and the other endemic areas include the Caribbean, Papua New Guinea, South America and Africa. After several decades of carrier state, patients may develop ATLL or HAM/TSP. Approximately half of ATLL patients have direct skin involvement of neoplastic cells manifesting patch, plaque, tumor, multiple papules, erythroderma and purpura $[1,2]$. However, there exist HTLV-1-associated reactive eruptions with a predominant infiltrate of non-neoplastic CD8+ T cells [2], such as chronic actinic dermatitis [4] and alopecia areata [5]. Here, we report recurrent diffuse facial erythema with CD8+ T cell infiltration in an HTLV-1 carrier.

\section{Case Presentation}

A 50-year-old Japanese woman was referred to us for evaluation of her facial eruption. The patient had had three episodes of the eruption during the past year. In each episode, itchy, indurated erythema occurred diffusely on the face and neck, lasted for 2 weeks and spontaneously subsided without sequelae. On the fourth episode, we observed an erythematous eruption with swollen palpebrae and cheeks (fig. 1a), which extended to the neck and earlobes (fig. 1b). Epidermal changes, including scale and papules, were minimal. Repeated inquiries did not give any possible contactants. Upon pregnancy, she was diagnosed as an HTLV-1 carrier. Her mother was also HTLV-1-positive. Leukocyte counts were normal without atypical lymphocytes, and the serum levels of lactate dehydrogenase and calcium were normal. C3, C4 and C1-INH were normal, negating the possibility of acquired angioedema associated with lymphoproliferative disorders [6]. By flow cytometry of the patient's peripheral blood mononuclear cells, CD4+ $(47.0 \%)$ and CD8+ cells $(21.7 \%)$ were within normal ranges. Cells bearing both CD4 and CD25 (10.9-16.5\%, measured at three different times), a marker for ATLL cells or regulatory T cells, were slightly increased, but there was no abnormal population distinct from normal CD4+ T cells (fig. 1c). The frequency of HLA-DR+CD8+ activated T cells was slightly increased $(6.2 \%$; normal $<3 \%)$. By Southern blot analysis of HTLV-1 proviral DNA, clonal integration was not detected in the peripheral blood mononuclear cells. Phototests with UVB showed normal minimal erythemal dose, and UVA did not induce erythema at $3 \mathrm{~J} / \mathrm{cm}^{2}$.

A biopsy specimen taken from the neck revealed a perivascular infiltrate of lymphocytes, showing exocytosis into the hair follicle epithelium (fig. 2a). They were CD3+ (fig. 2b), and some of them were positive for both CD4 (fig. 2c) and CD25 (fig. 2d), sharing the phenotype with ATLL neoplastic cells or regulatory T cells. Notably, an aggregate of CD8+ T cells (fig. 2e) bearing cytotoxic molecule TIA-1 (fig. 2f) was also observed.

\section{Discussion}

Our patient was an HTLV-1 carrier presenting with an unusual complication of transient facial erythema, histopathologically characterized by infiltration of CD8+ cytotoxic T lymphocytes (CTLs) intermingled with CD4+CD25+ T cells. This provides a possibility that skinaffinitive HTLV-1+CD4+ T cells propagated and subsequently disappeared as a result of CTL 
Kaneko et al.: Recurrent Facial Erythema with Cytotoxic T Cell Infiltration as a Possible Reactive Eruption in a Human T-Cell Lymphotropic Virus Type 1 Carrier

attack. Such an infiltrate of CD8+ T cells has also been reported in chronic actinic dermatitis [4] and alopecia areata [5] of patients with HAM/TSP and carriers.

In association with HTLV-1 infection, reactive eruptions induced by CD8+ T cells have been described. HTLV-1-associated infective dermatitis is a chronic exudative eczematous eruption prevalent in children of the Caribbean area and South America [7]. This disease is seen in HTLV-1 carriers, and some of the patients develop HAM/TSP. A recent study revealed that the infiltrate was composed of T cells with a predominance of CD8+ cells [8]. It is speculated that the eruptions mediated by CD8+ $\mathrm{T}$ cells can occur as a defensive reaction toward HTLV-1-infected cells. Although the recurrent facial erythema in our case is different from the skin manifestation of HTLV-1-associated infective dermatitis, both eruptions seem to share the CTL-based pathogenesis. Future accumulation of cases is required for explanation of the predilection site of face and neck in this condition.

\section{Statement of Ethics}

Flow cytometric analysis of peripheral lymphocytes was approved by the Ethical Committee of Hamamatsu University School of Medicine.

\section{Disclosure Statement}

The authors declare no conflicts of interest. There were no funding sources.

\section{References}

1 Sawada Y, Hino R, Hama K, Ohmori S, Fueki H, Yamada S, Fukamachi S, Tajiri M, Kubo R, Yoshioka M, Nakashima D, Sugita K, Yoshiki R, Shimauchi T, Mori T, Izu K, Kobayashi M, Nakamura M, Tokura Y: Type of skin eruption is an independent prognostic indicator for adult T-cell leukemia/lymphoma. Blood 2011;117: 3961-3967.

-2 Tokura Y, Sawada Y, Shimauchi T: Skin manifestations of adult T-cell leukemia/lymphoma: clinical, cytological and immunological features. J Dermatol 2014;41:19-25.

-3 Shimauchi T, Imai S, Hino R, Tokura Y: Production of thymus and activation-regulated chemokine and macrophage-derived chemokine by CCR4+ adult T-cell leukemia cells. Clin Cancer Res 2005;11:2427-2435.

-4 Sugita K, Shimauchi T, Tokura Y: Chronic actinic dermatitis associated with adult T-cell leukemia. J Am Acad Dermatol 2005;52(2 suppl 1):38-40.

5 Ito T, Shimada S, Mori T, Tokura Y: Alopecia areata possibly induced by autoimmune reaction in a patient with human T-cell lymphotropic virus-1-associated myelopathy. J Dermatol 2013;40:399-401.

-6 Castelli R, Zanichelli A, Cicardi M, Cugno M: Acquired C1-inhibitor deficiency and lymphoproliferative disorders: a tight relationship. Crit Rev Oncol Hematol 2013;87:323-332.

7 McGill NK, Vyas J, Shimauchi T, Tokura Y, Piguet V: HTLV-1-associated infective dermatitis: updates on the pathogenesis. Exp Dermatol 2012;21:815-821.

-8 Torres-Cabala CA, Curry JL, Li Ning Tapia EM, Ramos C, Tetzlaff MT, Prieto VG, Miranda RN, Bravo F: HTLV-1-associated infective dermatitis demonstrates low frequency of FOXP3-positive T-regulatory lymphocytes. J Dermatol Sci 2015;77:150-155. 


\section{Case Reports in Dermatology}

\begin{tabular}{l|l}
\hline Case Rep Dermatol 2015;7:95-99 \\
\hline DOI: 10.1159/000430804 & $\begin{array}{l}\text { C 2015 S. Karger AG, Basel } \\
\text { www.karger.com/cde }\end{array}$ \\
\hline
\end{tabular}

Kaneko et al.: Recurrent Facial Erythema with Cytotoxic T Cell Infiltration as a Possible Reactive Eruption in a Human T-Cell Lymphotropic Virus Type 1 Carrier
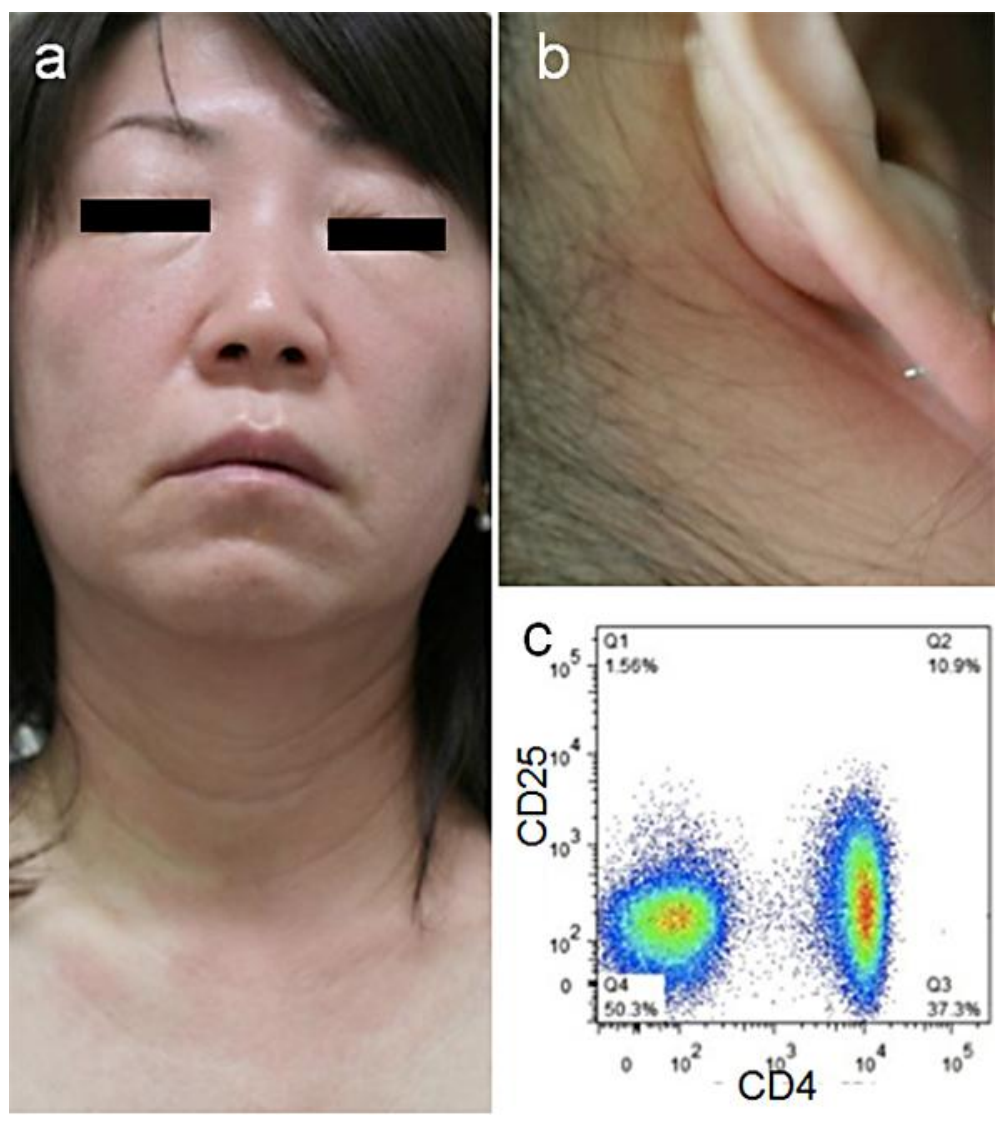

Fig. 1. Clinical appearance. a Erythema and edema on the face. $\mathbf{b}$ Erythematous lesions extending to the neck and earlobes. c Flow cytometric analysis of peripheral blood mononuclear cells showing a slightly increased frequency of CD4+CD25+ T cells (10.9\%) without a distinct expanding population. 


\section{Case Reports in Dermatology}

\begin{tabular}{l|l}
\hline DOI: $10.1159 / 000430804$ & $\begin{array}{l}\text { C 2015 S. Karger AG, Basel } \\
\text { www.karger.com/cde }\end{array}$ \\
\hline
\end{tabular}

Kaneko et al.: Recurrent Facial Erythema with Cytotoxic T Cell Infiltration as a Possible Reactive Eruption in a Human T-Cell Lymphotropic Virus Type 1 Carrier
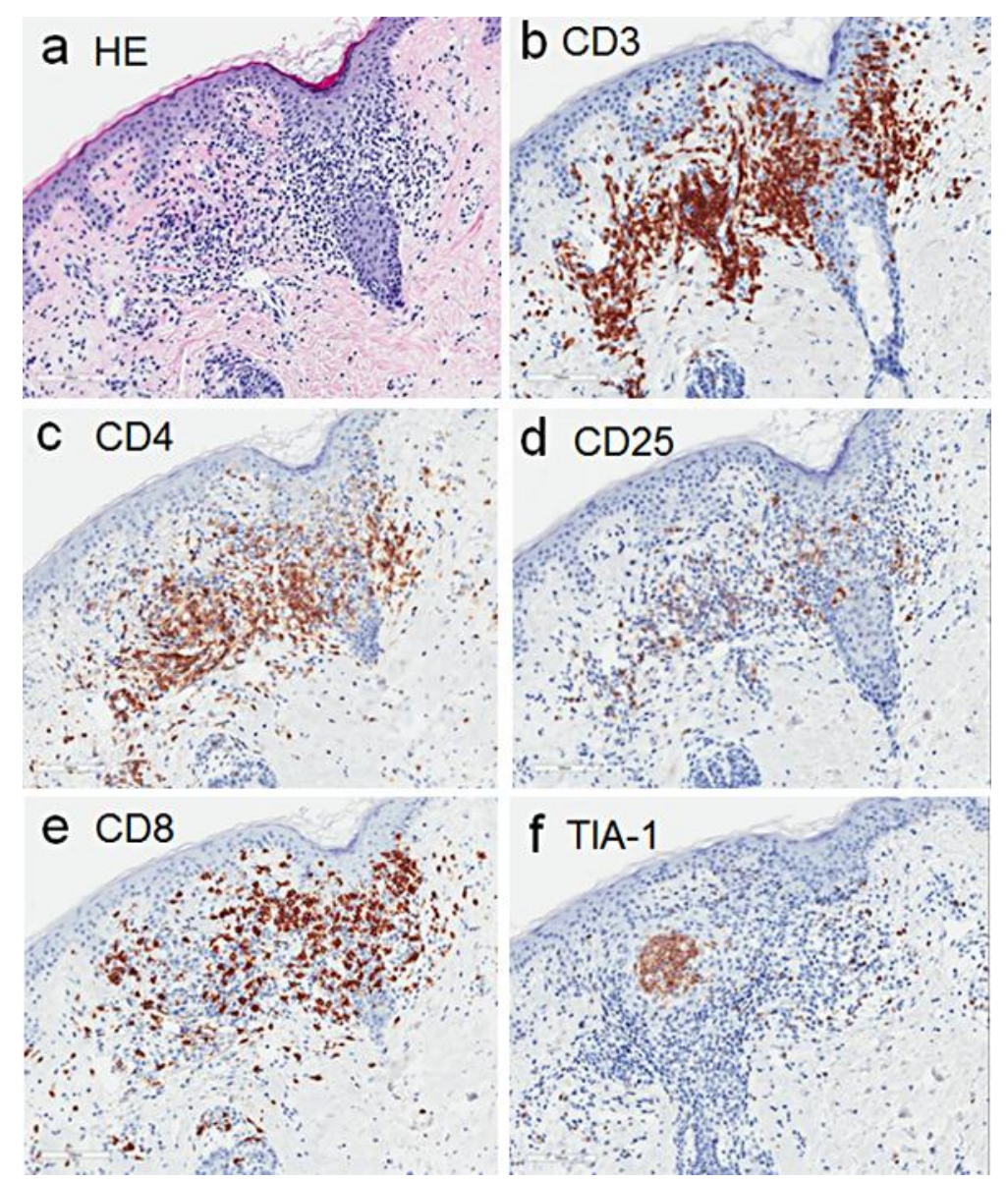

Fig. 2. Histopathological findings. a Histopathology of the cervical eruption showing a perivascular lymphocytic infiltrate and lymphocyte invasion into hair follicles (H\&E, $\times 100)$. b-f Immunohistochemical staining for CD3 (b), CD4 (c), CD25 (d), CD8 (e) and TIA-1 (f). 